\title{
Chapter 5: Fake News and Alternative Facts - A Constructivist Critique of the Current Right-Wing Populist Will to Truth
}

\author{
Stefan Neubert ${ }^{1} \&$ Kersten Reich ${ }^{1}$ \\ ${ }^{1}$ University of Cologne, Faculty of Human Sciences, Cologne, Germany \\ Correspondence: Stefan Neubert, University of Cologne, Faculty of Human Sciences, Gronewaldstraße 2, 50931 \\ Cologne, Germany. E-mail: s.neubert@uni-koeln.de, kersten.reich@uni-koeln.de
}

Received: August 30, 2017

Accepted:September 10, 2017

Online Published: March 7, 2018

doi:10.5430/irhe.v3n $1 \mathrm{p} 70$

URL: https://doi.org/10.5430/irhe.v3n 1p70

\begin{abstract}
This chapter focuses on rhetorical strategies employed in right-wing populist discourses like the talk about "fake news" and "alternative facts" most prominently used in the Trump campaign and in the first year of his presidency. We discuss what is at stake in current politics regarding the relation between power and truth and propose some perspectives for critical reflection. First, we explore the concept of truth from a prag matist and constructivist perspective. We argue that there is a fundamental and necessary distinction between relativism and arbitrariness. Second, we consider the role of facts and scientific results in culture and society and the role that markets play in the distribution and dissemination of information and beliefs in a consumer society. We refer to Foucault's critical concept of the "will to truth" in order to argue that there are standards and procedures regarding facts and beliefs in modern society - e.g., practices that have shown their relative success in the hard and soft sciences - that must be defended against arbitrary assults by right-wing propaganda. We conclude by considering the necessary connection between a plurastic concept of truth and democratic politics in the face of the current right-wing attempts to establish a regime of truth that is fundamentally detrimental to democracy.
\end{abstract}

Keywords: constructivism, prag matism, will to truth, anti-democratic rhetorical strategies, Michel Foucault, John Dewey

\section{Introduction}

In the contemporary global crisis of democracy and a rising right-wing populism, claims to truth appear as hotly contested stakes in political struggles with strong tendencies to define true and false views in one-sided and partial ways, paint the world in black and white, privilege opin ion over argumentation, insinuation over justification, and use labels like liar as weapons against critics and divergent views. All these tendencies are characterized by the attempt to dominate social and political realities by selective interests and redefine the reading of these realities through highly simplified perceptions. They are moved by wishes, emotions, demands, and desires of individuals confronted with the ambiguous life conditions of societies moving back and forth between solid and liquid modernity (cf. Bauman 2000). We observe today right-wing populism on a global scale as growing political movements that seem to appeal to the needs of a growing nu mber of people who are getting lost in the flows of social life and direly look for orientation, identity, escape from ambivalence and insecurity, and stable forms of belonging (cf. to the chapters 1 to 4 in this issue).

\section{Truth - Pragmatist and Constructivist Perspectives}

Liquid modernity is characterized by a cultural drift towards diversity, on the one hand, and growing economic dominance combined with social and political power of the super rich and strong, on the other hand. Donald Trump appears as the almost perfect symbol for the latter. These tendencies seem to have led to a dramatically new constellation in democratic societies - in some places more dominant than in others - in which democratically elected leaders implement populist policies and undermine democratic pillars like the division of forces, freedom of speech and press and other human rights, freedom of movement and other liberal rights, respect for diversity, participation, exchange and negotiation across borders, openness to the opinion of others, etc., and thereby put democracy itself at risk. 
It is striking to observe that one problem reappears in populis $\mathrm{m}$, on a political level, that had already earlier e merged in philosophical and scientific debates around subjectivism-namely the problem of arbitrariness. Yet this development, upon closer examination, is not all too astonishing. After all, science is itself part of society involved in the transition from solid to liquid modernity. We suggest, then, that it is useful to get back to some debates around the problem of arbitrariness in the more recent history of philos ophy and sciences.

Nelson Goodman (1978) describes the scientific drift toward diversity, conte xtualis $\mathrm{m}$, and relativis $\mathrm{m}$ in the following way: The loss of the one world of classical metaphysical thought turns out to be a loss of the one, accurate, and comprehensive version of world. The sciences and humanities are seen as versions of world making. In our constructivist terminology (cf. Reich 2009: $40 \mathrm{ff}$.), this is to say that the sciences and humanities - hard and soft sciences - depend on observers, participants, and agents in cultural contexts who provide different versions of worlds through the observations and actions in which they participate in their respective roles in discourses. There is a difference between the hard and the soft sciences regarding their current liquefication: while the hard sciences still remain largely successful in their attempts to confine contextualism and relativis m through rigid methods and thereby establish a comparatively strong mainstream of research and recognized results, the soft sciences have since long surrendered the search for certainty of consensus, unified methods, and unified approach in favor of more pluralistic approaches, discourses, and more contested methods and results. The respective advantages and disadvantages of both developments are themselves ambivalent. The hard sciences look through sharp lens es while often forgetting the world beyond their observations and the consequences and risks that their research and results may produce. Belief in progress often limits critical reflection, as in the case of new technologies that are introduced by scientific successes and become widespread cultural tools that in retrospect show unintended effects and dangers (Fukushima and the green-house effect are only among the most notorious examples). The soft sciences, by contrast, cultivate more multi-perspectival approaches to individual, social, cultural, political and other versions of reality in their diversity. This does not imply that they lose themselves in arbitrariness, but it makes them often more vulnerable to scientific as well as public and political pressures and expectations of warranted assertibility. In recent decades, there has been a continual loss of self-esteem and independence because in many cases the soft sciences tend to imitate and emulate the drift of the hard sciences. But despite this difference, they both have lost a last meta-observer as the ultimate source of legitimacy — be that a god or some allegedly final law or ultimate foundation projected into "outer reality." They are confronted by the predicament that there may be different accurate or right versions of the world coexisting at a given time or contending for each other's claims. There are no rational grounds for finding a common denominator for all of these versions, although within the respective approaches it is still possible to maintain conclusive logical argumentation and concise patterns of rationality. Therefore, Hilary Putnam (1992), in commenting on Goodman's work, insists on the necessity and legitimacy of formal assertions in science. But he agrees with Goodman that no s uch as sertion or statement can claim to represent a reality independent of experience. For Putnam, too, there is not one single true description of reality.

For some observers, this situation may easily call forth the nightmare of postmodern arbitrariness, because we can no longer make unambiguous truth claims with universal validity for everyone and in every context. But constructivists and pragmatists alike do not plea for arbitrariness. They rather attempt to inquire into the viability of reality constructions and their practical consequences. This implies that they also look for instrumental and experimental ways of constructing realities, lest viability turns into mere opinion, but leads to relevant, resourceful, and problem-solving constructions.

Following the argumentation in Reich (in Hickman/Neubert/Reich 2009: 40-42), we emphasize that constructivists do not look for copies of an outer reality in the human mind. Rather, they see humans as observers, participants, and agents who actively generate and transform the patterns through which they construct the realities that fit them. Although in everyday practices these constructions often appear to be merely subjective, we must not forget the social contexts in which they are always embedded; thus there is no such thing as purely subjective constructions, but constructions and versions of realities are always mixtures emerging from transactions with already existing (cultural and other) realities.

In science, we use specific discursive practices, methods, standards, evaluations, intersubjective justification, criteria of validity, reliability, and objectivity, to generate and control these transactions and constructions. Thereby, our scientific constructions are safe-guarded against merely arbitrary or subjective claims, although they depend on the unique and concrete perspectives of the observers, participants, and agents involved. With the transition from modernity to late modernity or liquid modernity (see Bauman 2000) and the attendant increase in degrees of freedom-as manifested in philosophical discourse, e.g., by the debates on deconstruction and poststructuralism - there is an increasing recognition of constructivist approaches. Interactive constructivists, to be 
sure, suppose that realities have been constructed in many and diverse ways in culture before our own time. We never construct from scratch. To the degree, however, that in more recent times radically diverse perspectives and versions of the world appeared in succession and juxtaposition, to the degree that even in science diversity could no longer be restricted by the temporary dominance of certain schools or traditions, the relativity of truth claims has more and more come to the fore. And with the acknowledgement of this relativity goes an increased consideration of both the constructive status of those claims and the singularity of the events to which reference was made.

This constructivist understanding of truth is strongly connected to Deweyan Prag matis m. Dewey already addressed the problem of arbitrariness in his philosophical reflections upon the contextualism of thinking. Jim Garrison argues that for Dewey's understanding of truth two aspects are very important:

"First, there are no intuitive, immediate, or self-evident truths for Dewey. Second, truth is not a matter of the correspondence of a proposition to a state of affairs such as we find in the classical correspondence theory of truth. It is a functional correspondence of means to ends, which is very different from the standard correspondence theory. Here is a statement of what Dewey means by truth: 'Sometimes the use of the word 'truth' is confined to designating a logical property of proposition; but if we extend its significance to designate character of existential reference, this is the meaning of truth: processes of change so directed that they achieve an intended consummation. Instrumentalities are actually such only in operation ... The means is fully a means only in its end' (LW 1:128). Truth in its existential sense is a course of constructed operations yielding the same consequences every time and everywhere. To avoid entanglement with the usual theories of truth, Dewey will turn to "warranted assertion" in his 1938 Logic. There, knowledge is simply the product of a process of inquiry. Now, warranted as sertion concerns knowledge here; not truth per se, but knowledge is the end of inquiry, and we may warrant a knowledge claim if the same operations using the same means produce the same end of knowledge every time (given the constraints of context). I like to take constructivism very literally. We construct meanings in our sociolinguistic practices and we construct truth as the product of the operations in a process of inquiry (i.e., the formation of judgment). That Dewey often refers to industrial operations and the like when explaining what he means by operations seems very significant to me. To say we socially construct meaning and from meanings we construct warranted assertions (knowledge, things we assert as true with warrant) does not mean we can make anything true we want. It is usually very hard to find constructions that, in fact, succeed in transforming some problematic situation. If we can figure out a course of operations that are stable, repeatable, and reliably produce the same end every time, then we have good warrant to say we have worked out 'processes of change so directed that they achieve an intended consummation.' I think what Larry Hickman has written on Dewey's philosophy of technology bears much more on this question than it seems. We produce warranted assertions in the process of forming judgment, much as we produce automobiles that run well." (Garris on in Hickman/Neubert/Reich 2009: 194-195)

Larry Hickman explains in this context:

"Peirce, James, and Dewey had somewhat different notions of truth, or at least they expressed the core ideas of Prag matism's treatment of the subject somewhat differently. In a 1941 reply to Bertrand Russell, Dewey is quite clear. Truth is defined as warranted assertibility. Truth is not subjective, but objective in the sense that there are many things that are assertible with warrant whether or not we wish them to be so. Truth is not the correspondence of an idea with a preexisting, extra-mental fact, nor is it the coherence of an idea within a system of thought. Truth is backward-looking in the sense that what is true is so because of the experimental work that has led to its status as warranted. It is also forward-looking in the sense that what is true is assertible. A warranted idea can be asserted in a context in which it is relevant and so serve to resolve a problematic situation.” (Hickman in Hickman/Neubert/Reich 2009: 195)

In the philosophical and scientific debates, then, we find in many variations a tendency towards moderately relativistic positions that respond pluralistically to diversity, ambivalence, dynamics in scientific processes and results as well as in the larger social life in which they are embedded. Th is moderate relativism emphasizes the need of contextualis $m$ that pervades all practices, methods, and discourses to warrant assertions. The process of inquiry in the hard as well as in the soft sciences is based on intersubjective procedures that follow at best fundamental democratic principles of transparency, debate, participation, negotiation, and conviction by argument and proof. Even if often in science the majority of opinions succeeds in establishing mainstream for a time, the history of science shows that it cannot prosper in the long run and prevent stagnation unless it pays regard to minority and even subjective claims and positions that show their warranted assertibility and win the approval by others within a diverse community. 


\section{Facts and Alternative Facts in Culture, Society, and the Market Place}

Warranted assertibility in the Deweyan sense implies that facts and beliefs - in culture generally as well as in the hard and soft sciences in particular - are always responses to specific contexts. In a methodological excursus contained in the unfinished book project Unmodern Philosophy and Modem Philosophy (Dewey 2012) from the 1940s recently edited and published by Phillip Deen, Dewey gives an informative account of the social and cu ltural emergence or construction of facts, beliefs, and problems. (Note 1) He elaborates on a pragmat ist theory of observing when he notes that in concrete cases of observation - like perceiving "a wire strung along on poles by the highway" as part of a telephone or telegraph network - "we recognize the dependence of the event of observing and of what is observed upon the antecedent existence of a constellation of habits, including attitudes of belief operating as facilities, resources" (Dewey 2012: 138). He points out that it is important to understand that the observation of an event "which gives it rank as fact (which is a precedent condition of noting ... a problem)" depends on conditions that are determined by social practices "including language, or the meanings current as means and material of communication" (ibid.). His social constructivism is apparent, here - facts as well as problems are socially constructed (see also Garrison 2009; Neubert/Reich 2006; Hickman/Neubert/Reich 2009). Dewey pretty well summarizes his social constructivist theory of observing in the sentence that follows: "The true statement that we know (observe) with what we have known (that is, learned) needs to be supplemented by recognition that what is learned is a function of the social group and groups of which one is a member." (Dewey 2012: 138) He even speaks of a cultural relativity "of beliefs, facts and problems" which must not be confused with the idea that beliefs are arbitrary and all of equal value (ibid.: 139). Relativity does not exclude comparison and evaluation of beliefs and practices. Rather, as Dewey observes, the "fact of relativity is an indirect way of calling attention to the differences which exist in the attitudes and practices of different cultural groups as to the methods and criteria by which their beliefs are respectively reached and modified" (ibid.).

A scientific community as well as a religious sect implies a cultural context of observing, participating, and acting under specific cultural conditions. There is no difference with regard to this general condition of cultural relativity. Yet, there is all the difference in the world between both groups with regard to the methods used, the criteria employed, the attitudes formed, and the practices performed in the constitution and formation of beliefs. By implication Dewey's argumentation contains a distinction that has been articulated more explicitly and systematically in the Cologne program of interactive constructivism (cf. Garrison/Neubert/Reich 2012, 2016). The interconnected roles of observers, participants, and agents are helpful for a constructivist account of the cultural and scientific construction of facts, beliefs, and problems. Regarding cultural relativity of truth and knowledge claims, Dewey refers to a somewhat extreme example to illustrate a general point.

"We are familiar, in some cases only too much so, with the existence of sects, parties, denominations, factions, schools, cliques, sets, economic classes, 'organizations.' We are also aware that each one of these consists of human beings who in that particular capacity are followers, adherents, votaries, devotees, partisans" (Dewey 2012: $138 \mathrm{f})$.

Obviously, the latter terms refer to the participant role that informs and influences observation and action.

Dewey further specifies this participant role by observing that upon reflection it becomes obvious that these groups are in formed and constituted by commonly held "formulated doctrines, creeds, tenets, platforms, etc." (Ibid.: 139). He explains that he has used these examples because they specifically help understand the necessary relation between participant and observer perspectives, for "it is so obvious in their case that the belief that determines what is admitted and excluded as facts and the manner in which observation is carried on (including deflections and distortions ...) is a matter of group, constitution and behavior" (ibid.). If we look at these groups and their beliefs and observations from outside - as distant observers, to use the term of the Cologne interactive constructivism program we will probably find that at least in some of these cases the influence between participation and observation "suggests undesirable, objectionable qualities" - especially in the case of those groups "with which we do not agree" (ibid.). However, for the purpose of our present intention, the most important point of Dewey's argumentation lies not in this critical view on specific cases of rather narrow partisanship, but in the general conclusion that he draws from these considerations with regard to a necess ary cultural self-criticism:

I have used these cases because their somewhat extreme character illustrates the sort of thing which happens in all cases, including those which are regarded as highly desirable. For the contrast between the undesirable and the desirable is not that of determination of belief-constellations (and consequent facts and problems) in one case by socio-cultural conditions and in the other case by mind or intellect free from any such social 
influence but is that between habits and the attitudes which are characteristic of the methods used by different groups. (Dewey 2012: 139; ital. ours)

Dewey's insistence on the necessary contextuality of facts and problems reminds us that in any case, as humans, we are participants, agents, and observers in culture, and that our participation influences our observations and actions as well as the other way around. "In the etymological sense of the word, all of us are partisans in that we are parts along with others, of groups which are with respect to their 'parts' wholes of a sort." (Dewey 2012: 139)

Against this background facts are not simply given but always imply aspects like cultural backgrounds, habits, selective interests, established procedures that especially in the hard sciences appear as relatively solid and stable. We may often tend to forget that even the hard sciences depend on cultural contexts. If you think for example of a natural science laboratory, already the concrete practices of research depend on established habits, routines, institutions, attitudes of observation and communication, taken for granted beliefs, expectations of costs and benefits, etc. In addition, the social and cultural contexts also include factors like the individual career plans of agents, the social climate between participants which influences the ways in which they articulate, share, and elaborate their observations. Even in the sciences we often observe cases of deception and fraud to gain personal advantage. Facts can be faked and beliefs can be manipulated.

When we think of the notorious story of how the term "alternative facts" became apparent right on the occasion of his inauguration ceremony, it seems that Donald Trump and his team have all too well understood the lesson of cultural relativity and turned it into a weapon of a right-wing assault on truth claims. Against the background of our argumentation so far, however, we must insist that there is a necessary distinction between recognizing the cultural relativity of facts and beliefs and the indulgence to merely arbitrary claims that simply follow one's wishes and interests by ignoring and denying the observations and the warranted assertibility given by others - in this case the mu ltitude of witnesses who observed that the number of attendants were considerably less than in the case of Obama. There are criteria and procedures in any society to tell truth from false even if these criteria and procedures are cultural dependent.

In this connection, it is useful to refer to Michel Foucault's term "will to truth" in order to complement our reflections. With Foucault, we observe that the cultural relativity of facts and beliefs is irresolvably connected with relations of power. This is true not only for Donald Trump and his campaign, but applies to all cases of observation and statement of facts and beliefs. However, it makes a significant difference from a social and democratic point of view, which forms of will to truth obtain in a given society. There is a long tradition in the development of sciences that the appropriate will to truth is guaranteed as well as controlled and limited by scientific communities that negotiate the appropriate procedures of stating facts and testing beliefs. The development of science has shown that these communities must be open to diversity and even to minority positions if they wish in the long run to achieve success and progress in the constructions of truth and knowledge.

However, in the history of modern societies, the ideal-typical image of the scientific community has always been contested by individual and corporative interests of gains, profits, careers, success, etc. Capitalis $m$ and the market society have been the frames of all these developments. In this context, truth is what sells, and a certain amount of illusions, deceptions, and frauds are included in all practices of producing and exchanging goods and values. It is no wonder, therefore, that we can observe not only a necessary tension between democracy and capitalism, but also between truth claims and the market.

In a consumer society, as described by Bauman, the shopping mall and other consumerist temples have gained an important role and even serve as an epitome of living in liquid modernity. In his analysis of forms of capital as conditions for contemporary capitalis m and consumeris m, Reich (2018) has introduced the distinction between illusion, deception, and fraud as ways of generating surplus values and profits beyond the mere exploitation of workforce. The generation of profits always has its individual as well as social dimension. Illusion means that ways of sugar-coating as well as omission in order to suggest imag inary advantages in comparison with compe ting offers and agents. Examples include commercial advertising and the playful aesthetics of commodities, services, individual qualities of goods and persons. Deception means a further increase that includes the intentional deceiving and misleading of consumers and users by stirring one-sided assumptions and expectations, pretending achievements and promising results that cannot be sustained, and veiling unpleasant, unhealthy or otherwise detrimental consequences. While illusions are normally below the level of legal sanction, deception often transgresses the border to penal prosecution. However, deception has become so much common practice in contemporary in market societies that we often find a legal gray area around it. With fraud, we enter an area that is clearly criminal. As always with criminal acts, prosecution depends on the decisions as well as means of legal agents and institutions to do their job. 
If we come back to the example of Trump's inauguration ceremony, we may say that only good-willing observers, mainly his own whole-hearted supporters, will believe that the alternative facts are real and all other interpretations are hostile. As witnesses who observe from a distance and compare the alternative facts with other documented facts, we will at least say that the generated impression is an illusion. When we consider that the White House obtrusively maintains its interpretation despite all facts documented by diverse observers and witnesses in civil society, we have a right to speak of intentional deception. Critical observers may even use the term fraud if they think of the instance being part of a larger right-wing agenda that aims at destroying democratic principles, liberties, and institutions in the name of the alleged support by the multitude.

\section{Pluralistic Concept of Truth and the Political}

Donald Trump, who claims to lead his country like a big boss leads a company, obviously believes that market mechanis $\mathrm{m}$ in a consumer society including the dimensions of illusion, deception, and fraud equally apply to politics. Unfortunately, he is not the only one but only one very extreme example of tendencies also shown by others. It shows an inherent pattern of capitalis $m$ that indicates a fundamental tension between capitalis mand democracy, and can, at times, constitute an eminent threat to democratic society itself. One of the strongest dangers that we can see in Trump's presidency, so far, is that it helps to establish a right-wing hegemony that demolishes democratic culture to an extend that democracy can no longer defend itself against the mechanisms of illusion, deception, and fraud.

Speaking with Foucault, what is at stake here is the right-wing attempt to establish a regime of truth. The rhetoric strategies of "alternative facts" and "fake news" are part and parcel of this regime and they help to undergird its fundaments. Seen in a larger perspective, the recent renaissance of nationalism and the global wave of right-wing populism have dramatized a challenge that has always been embedded in the tensional relations between capitalism and democracy. The core of this challenge consists of the tension between selective interests as produced, articulated, and realized by practices of capitalism, on the one hand, and general interests and claims to human rights as constitutive for the democratic project, on the other hand. In a globalized world, this tension clearly appears, for example, in the conditions of migration. Consider the case of refugees, some of them struggling for bare survival, others seeking for a better future without being marg inalized, exploited, and discriminated, still others looking for wealth and social ascent. At least, those committed to democratic principles must defend the hu man right of the first group to achieve shelter, asylum, nurture, and a safe perspective of living. But the lines cannot be drawn so neatly anyway. In all democratic societies the selective interests and vested rights of the populace and powerful economic and political groups and agents must be balanced with the general claims to human rights lest democracy loses its openness and adopts traits of a corral. Or consider the example of the right to work to earn a living that is independent and sustainable. It is striking that even though this right might be cons idered as self-evident from a democratic standpoint, it has not yet achieved the status of recognized human right in the history of capitalist societies. Again, selective capitalist interests stand against general democratic claims. Combining Dewey's idea of democracy and Bauman's description of ambivalence in liquid modernity, we may distinguish between democracy de jure and democracy de facto. Against this background, the democratic challenge that the present global political crisis shows is a twofold one: First, democracy de jure consists of legal, economic, social, cultural, educational, and political claims and institutions achieved in long struggles, exemplarily represented by the human rights, that must be defended against attacks on the very grounds they rest on. These grounds include a will to truth that considers facts, beliefs, interpretations, opinions as the product of democratic negotiations among diverse perspectives and observations in a pluralistic society. Among these grounds are further the warranted procedures, institutions, and practices, as manifested in the division of forces, independent courts and press, pluralistic formation of opinions, responsible and open journalism, scientific communities, inclusive education, all of which participate in the necessary constant reconstruction of democracy. The populist attack on democratic culture by means of claims to "alternative facts" and "fake news" charges must be seen as an attack on these very fundaments of democracy de jure. From a democratic standpoint, we can detect and denounce these attacks as anti-liberal even if from a constructivist standpoint we concede that the democratic standpoint is itself a cultural construction de jure. What is more, with Dewey we need to remind ourselves that the most important thing about democracy is not its claim de jure, but its realization de facto. We might even suppose that the very gap between de jure and de facto, in this case, is what causes the susceptibility of many people for reductionist and illus ionary answers given by populists. The democratic response can only be twofold as well: We need to defend and further develop the grounds of democracy de jure, and we need to intensify and diversify the struggles for genuinely democratic conditions de facto of life on all levels. But in our view democracy is not a tale of reconciliation. The tension between democracy and capitalis $m$ and with it the contrast between claims de jure and conditions de facto remains, and we can hard ly expect that it will easily dissolve in the future. 


\section{References}

Citations of the works of John Dewey are to the critical edition, The Collected Works of John Dewey, 1882-1953, published by Southern Illinois University Press, Carbondale and Edwards ville.

Volume and page numbers follow the initials of the series. For instance, MW 9: 1. Abbreviations for the volumes used are:

EW $\quad 1-5=$ The Early Works (1882-1898), Vol. 1-5

MW 1-15 = The Middle Works (1899-1924), Vol. 1-15

LW 1-17 = The Later Works (1925-1953), Vol. 1-17

Supplementary Volume 1: 1884-1951

\section{Other References}

Bauman, Z. (2000). Liquid Modernity. Cambridge, U.K.: Polity Press.

Dewey, J. (2012). Unmodern Philosophy and Modern Philosophy. In Phillip Deen (Ed.), With a foreword by Larry A Hickman. Carbondale and Edwards ville (Southern Illinois University Press).

Garrison, J. (2009). Dewey's Constructivism: From the Reflex Arc Concept to Social Constructivism, Hickman, L.A., Neubert, S., \& Reich, K. (Eds.), pp.84-105.

Garrison, J., Neubert, S., \& Reich, K. (2012). John Dewey's Philosophy of Education: An Introduction and Recontextualization for Our Times. New York: Palgrave Macmillan.

Garrison, J., Neubert, S., \& Reich, K. (2016). Democracy and Education Reconsidered-Dewey After One-Hundred Years. New York, Routledge.

Goodman, N. (1978). Ways of Worldmaking. Indianapolis (Hackett Publishing Company).

Hickman, L.A., Neubert, S., \& Reich, K. (Eds.) (2009). John Dewey Between Pragmatism and Constructivism. New York (Fordham University Press).

Neubert, S., \& Reich, K. (2006). The Challenge of Pragmatism for Constructivism: Some Perspectives in the Programme of Cologne Constructivism. In Journal of Speculative Philosophy (JSP) (Volu me 20, Nu mber 3, pp. 165-191). New Series.

Putnam, H. (1992). Realism with a Human Face. Edited by James Conant. Cambridge (Mass.) \& London (Harvard University Press).

Reich, K. (2009). Constructivism: Diversity of Approaches and Connections with Prag matis m, Hickman, L.A., Neubert, S., \& Reich, K. (Eds.), pp.39-64.

Reich, K. (2018). Surplus Values-A New Theory of Forms of Capital in the Twenty-First Century. Cologne: University of Cologne. Retrieved from http//: www.uni-koeln.de/hf/konstrukt/english/surplus_value/index.html

\section{Note}

Note 1. Compare our more extended discussion in Garrison/Neubert/Reich (2016: chapter 7). 